\title{
Efektifitas Pelaksanaan Whistleblowing System sebagai Upaya Pencegahan Tindakan Korupsi di Rumah Sakit Ortopedi Soeharso Surakarta
}

\section{The Effectiveness of Implementing Whistleblowing System as an Effort to Prevent Corruption at Soeharso Ortopedic Hospital Surakarta}

\author{
Lutfiyah Rizqulloh $^{1}$, Frieda Ani Noor ${ }^{2}$, Muhammad Iqbal ${ }^{3}$ \\ Program Studi Administrasi Kesehatan, Universitas Kusuma Husada Surakarta ${ }^{1,2}$ \\ Program Studi Kesehatan Masyarakat, Universitas Dian Nuswantoro ${ }^{3}$ \\ Email:lutfiyah.rizqulloh@gmail.com
}

\begin{abstract}
The prevention of corruption that the world is currently doing is by implementing a whistleblowing system. The implementation of whistleblowing in the health sector in Indonesia has begun to be implemented at the district/city health offices, hospitals, and BPJS Kesehatan. Whistleblower actions around the world have brought several changes in the hope that each sector will become good governance. This study aims to determine the effectiveness of the implementation of the whistleblowing system as an effort to prevent criminal acts of corruption at Soeharso Orthopedic Hospital, Surakarta. Soeharso Orthopedic Hospital, Surakarta, has implemented a whistleblowing system since 2014 as part of an integrated public complaint handling system that focuses on handling suspected corruption crimes. The research method used was quantitative research by distributing questionnaires to 52 employees at Soeharso Orthopedic Hospital Surakarta. The results showed that the program objectives were appropriate in implementing the Whistleblowing System at the Soeharso Orthopedic Hospital in Surakarta, the program socialization was carried out by the Internal Supervisory Unit of the Soeharso Orthopedic Hospital in Surakarta by socializing the whistleblowing system complaint method easily and easily accessible, the aim of the whistleblowing system reporting program. At the Soeharsa Orthopedic Hospital in Surakarta, it has been accomplished that the goal is to stop corrupt behavior and as an effort to prevent corruption, monitoring programs carried out by the Internal Supervisory Unit have been carried out in monitoring all reports of criminal acts of corruption on the website http://pbak.rso.go.id/
\end{abstract}

Keywords: korupsi, whistleblowing system, rumah sakit, whistleblower

\begin{abstract}
ABSTRAK
Pencegahan korupsi yang dunia saat ini lakukan adalah dengan menerapakan whistleblowing system. Pelaksanaan whistleblowing pada bidang kesehatan di Indonesia sudah mulai diterapkan pada tingkat dinas kesehatan kab/kota, rumah sakit, maupun BPJS Kesehatan. Tindakan whistleblower di seluruh dunia telah membawa beberapa perubahan dengan harapan tiap sektor menjadi tata kelola yang baik (good governance). Penelitian ini bertujuan mengetahui efektifitas pelaksanaan whistleblowing system sebagai upaya pencegahan tindak pidana korupsi di Rumah Sakit Ortopedi Soeharso Surakarta. Rumah Sakit Ortopedi Soeharso Surakarta sudah menerapkan pelaksanaan whistleblowing system sejak tahun 2014 sebagai bentuk bagian dari sistem penanganan pengaduan masyarakat terpadu yang memfokuskan pada penanganan dugaan tindak pidana korupsi. Metode penelitian dengan penelitian kuantitatif melakukan penyebaran kuesioner kepada pegawai di Rumah Sakit Ortopedi Soeharso Surakarta sebanyak 52 orang. Hasil penelitian didapat bahwa sasaran program sudah tepat dilakukan dalam melaksanakan Whistleblowing System di Rumah Sakit Ortopedi Soeharso Surakarta, sosialisasi program telah dilakukan oleh Satuan Pengawas Internal Rumah Sakit Ortopedi Soeharso Surakarta dengan mensosialisasikan metode pengaduan whistleblowing system dengan mudah dan mudah diakses, tujuan program pelaporan whistleblowing system di Rumah Sakit Ortopedi Soeharsa Surakarta sudah terlaksana bahwa tujuannya untuk menghentikan perilaku tindakan korupsi dan sebagai salah satu upaya mencegah tindak korupsi, pemantauan program yang dilakukan oleh Satuan Pengawas Internal sudah terlaksana dalam melakukan pengawasan terhadap semua laporan tindak pidana korupsi di website http://pbak.rso.go.id/
\end{abstract}

Kata kunci: korupsi, whistleblowing system, rumah sakit, whistleblower 


\section{PENDAHULUAN}

Indonesia masih memiliki angka korupsi yang cukup tinggi beradasarkan data dari Corruption Perception Index tahun 2018 menduduki skor 38/100 dengan peringkat ke 89 dari 180 negara (Transparency International, 2018). Tingginya tingkat korupsi di Indonesia terutama pada pengadaan barang dan jasa. Data dari KPK menunjukkan bahwa tindak pidana korupsi berdasarkan jenis perkara korupsi dari tahun 2004-2017 paling besar adalah penyuapan 358 kasus dan terbesar kedua adalah pengadalaan barang atau jasa 169 kasus (Anti-Corruption Clearing House., 2017).

Kasus korupsi pada bidang kesehatan sangat tinggi dalam pengadaan barang dan jasa dengan modus markup yang menimbulkan kerugian negara sangat banyak. Berdasarkan data dari Indonesia Corruption Watch tahun 2017 modus korupsi dibidang kesehatan adalah markup atau penggelembungan harga pengadaan barang dan jasa tercatat 93 kasus dengan kerugian negara mencapai Rp 512,9 Milliar (Indonesia Corruption Watch, 2017). Peningkatan anggaran kesehatan dari tahun ke tahun dalam pengelolaan anggaran di bidang kesehatan rawan praktek korupsi. Berdasarkan data dari Kementerian Keuangan Kementerian Kesehatan masuk dalam sepuluh kementerian dengan anggaran terbesar pada tahun 2020. Anggaran Kementerian Kesehatan tahun 2020 sebesar 57,4 T dengan mencapai pemenuhan anggaran kesehatan 5\% dari Anggaran Pendapatan dan Belanja Negara (Kementerian Keuangan, 2020).

Tindakan korupsi dibidang kesehatan paling banyak pada kasus alat kesehatan, pembangunan atau rehabilitasi obat, jaminan kesehatan, dan pembangunan atau rehabilitasi puskesmas atau rumah sakit yang bersumber dari dana kuratif yang memiliki presentasi paling besar dalam APBN dan APBD Kesehatan (Indonesian Corruption Watch, 2018). Tersangka pada kasus korupsi kesehatan diantaranya kementerian kesehatan, dinas kesehatan kabupaten/kota/provinsi, rumah sakit, BPOM, puskesmas, BUMN/BUMD kesehatan.

Berdasarkan data dari Global Corruption Barometer tahun 2017 bahwa sektor kesehatan dipersepsikan korup oleh masyarakat hal ini mengalami peningkatan dari tahun 2013 sebesar 12\% menjadi 15\% pada tahun 2017 (Transparency International, 2017) . Maraknya kasus korupsi dibidang kesehatan di Indonesia membuktikan masih banyaknya kecurangan yang dilakukan seseorang untuk mendapatkan sesuatu keinginannya dengan menghalalkan segala cara.

Pencegahan korupsi yang dunia saat ini lakukan adalah dengan menerapakan whistleblowing system (Marcia P. Miceli, Janet P. Near, 2009). Whistleblowing system merupakan pengungkapan oleh anggota organisasi maupun diluar organisasi tentang praktik ilegal, tidak bermoral atau tidak sah yang telah terjadi atau akan terjadi melibatkan yang merugikan banyak orang (Srividhya and Stalin, 2012). Orang yang melaporkan atas korupsi, kejahtaan, dan pelanggaran lainnya termasuk perilaku tidak etis disebut whistleblower (Malek, 2015). Miceli et al (2012) menjelaskan bahawa komitmen organisasi yang tinggi pada pegawai akan menimbulkan rasa memiliki organisasi yang tinggi pula, sehingga ia tidak akan merasa ragu untuk melakukan whistleblowing.

Penerapan whistleblowing system di Indonesia sudah terintegrasi dengan Komisi Pemberantasan Korupsi (KPK) dan Lembaga Perlindungan Saksi dan Korban (LPSK). Program integerasi yang diberi nama TEGAS (Terintegerasi Antar Sistem) merupakan amanat intruksi Presiden Nomor 10 tahun 2016 tentang Aksi Pencegahan dan Pemberantasan Korupsi tahun 2016 dan 2017 yang mengintegrasikan whistleblowing system terkoneksi online. Terdapat 17 Kementerian yang sudah bergabung dalam integrasi tersebut salah satunya Kementerian Kesehatan. Pelaksanaan whistleblowing system di bidang kesehatan saat ini tidak hanya pada tingkat kementerian saja akan tetapi rumah sakit, dinas kesehatan kabupaten/kota, BPJS Kesehatan sudah mulai menerapkan 
whistleblowing sebagai bentuk penguatan komitmen dalam meningkatkan pemerintahan yang baik (Good Governance) agar terhindar dari tindak pidana korupsi.

Kementerian Kesehatan menerapkan sistem pelaporan whistleblowing system sebagai salah satu alat untuk mempercepat tercapainya Wilayah Bebas Korupsi (WBK) yang merupakan amanat dari Inpres Nomor 5 tahun 2004 tentang Pencegahan dan Pemberantasan Korupsi. Rumah Sakit Orthopedi Prof. Dr. R. Soeharso, Surakarta mendapatkan predikat penghargaan dari Kementerian Kesehatan tahun 2017 sebagai Wilayah Bebas dari Korupsi (WBK) dengan salah satu indikatornya menerapkan whistleblowing system. Whistleblowing system yang dilaksanakan Rumah Sakit Orthopedi Prof. Dr. R. Soeharso, Surakarta sudah berjalan tiga tahun sejak 2017-2020. Pelaksanaan WBS ini perlu dilakukan evaluasi dalam penerapannya, sehingga perlu dilihat seberapa efektif penerapan WBS dalam menunjang pelaksanaan Wilayah Bebas dari Korupsi sebagai upaya pencegahan tindak pidana korupsi.

\section{METODE}

Penelitian ini menggunakan metode kuantitatif dengan pendekatan cross sectional. Populasi pada penelitian adalah 508 orang karyawan di Rumah Sakit Ortopedi Soeharso Surakarta, yang terdiri dari 37 orang tenaga medis, 186 orang tenaga paramedis perawatan, 91 orang tenaga paramedis non perawatan, dan 194 orang non perawatan. Besar sampel pada penelitian menggunakan rumus Slovin karena populasi relatif homogen sehingga tidak terlalu diperlukan untuk distratifikasi dan terdapat jumlah populasi yang jelas. Total sampel adalah 52 orang.

\section{HASIL DAN PEMBAHASAN}


Responden dalam penelitian ini adalah pegawai Rumah Sakit Ortopedi Soeharso Surakarta pada tenaga Medis, tenaga Paramedis Perawatan, tenaga Paramedis Non Perawatan, tenaga non perawatan, dan yang berjumlah sampel 52 orang. Karakteristik dalam penelitian meliputi tingkat pendidikan, jenis kelamin, usia, dan lama kerja dapat disajikan pada tabel sebagai berikut :

Tabel 1. Distribusi Frekuensi Karakteristik Responden Rumah Sakit Ortopedi Soeharso Surakarta

\begin{tabular}{lcc}
\multicolumn{1}{c}{ Karakteristik } & Jumlah (n) & Persentase (\%) \\
\hline Pendidikan Responden & 17 & 32.7 \\
D1-D3 & 27 & 51.9 \\
S1 & 8 & 15.4 \\
S2 & 23 & \\
Jenis Kelamin Responden & 29 & 44.2 \\
Laki-laki & & 55.8 \\
Perempuan & 12 & \\
Umur Responden & 17 & 23.1 \\
$24-29$ & 10 & 32.7 \\
$30-37$ & 13 & 19.2 \\
$38-45$ & & 25.0 \\
$>46$ & 19 & \\
\hline Lama Kerja Responden & 15 & 36.5 \\
$1-7$ & 12 & 28.8 \\
$8-14$ & 5 & 23.1 \\
$15-21$ & 1 & 9.6 \\
$22-28$ & & 1.9 \\
$29-35$ & & \\
\hline
\end{tabular}

Distrisbusi tingkat pendidikan responden paling banyak responden berpendidikan S1 yaitu 27 orang $(51,9 \%)$ sedangkan untuk pendidikan D1-D3 dan S2 masing-masing adalah 32,7 \% dan 15,4\%. Jenis kelamin responden di Rumah Sakit Ortopedi Soeharso Surakarta paling banyak yaitu perempuan 29 orang (55,8\%) dan laki-laki 44,2\%. Usia responden Rumah Sakit Ortopedi Soeharso Surakarta paling banyak di usia 30-37 tahun sebanyak 17 orang $(32,7 \%)$ dan paling sedikit pada usia 38-45 tahun (19,2\%). Lama kerja Rumah Sakit Ortopedi Soeharso Surakarta paling banyak 1-7 tahun yaitu 19 orang $(36,5 \%)$ dan paling sedikit $29-35$ tahun $(1,9 \%)$.

Efektivitas Pelaksanaan Whistleblowing System Sebagai Upaya Pencegahan Tindakan Korupsi di Rumah Sakit Ortopedi Soeharso Surakarta

Uraian mengukur efektivitas pelaksanaan Whistleblowing System di Rumah Sakit Ortopedi Soeharso Surakarta menggunakan empat indikator yang meliputi:

\section{Ketepatan Sasaran Program}

Ketepatan sasaran program merupakan target dari pelaksanaan Whistleblowing System di Rumah Sakit Ortopedi Soeharso Surakarta yang hendak dicapai. Menganalisis dan menetukan efektivitas mengenai ketepatan sasaran program terdapat sebagai berikut : 
Tabel 2. Distribusi Responden Berdasarkan Ketetapan Sasaran Program

\begin{tabular}{clcc}
\hline No & Kategori & Frekuensi $(\mathbf{F})$ & Persen $(\%)$ \\
\hline 1. & Tidak Tepat & 23 & 44,2 \\
2. & Tepat & 29 & 55,8 \\
\hline Total & & 52 & 100 \\
\hline
\end{tabular}

Berdasarkan pada tabel diatas bahwa dari 52 responden yang menjawab terdapat 29 responden dengan presentase 55,8\% sudah merasa tepat dalam program pelaksanaan Whistleblowing System di Rumah Sakit Ortopedi Soeharso Surakarta. Ketepatan sasaran program, yaitu sejauh mana peserta program tepat yang sudah ditentukan sebelumnya. Menurut (Makmur, 2011) ketepatan sasaran lebih berorientasi kepada jangka pendek dan lebih bersifat operasional, penentu sasaran yang tepat baik ditetapkan secara indvidu maupun sasaran yang ditetapkan organisasi sesungguhnya sangat menentukan keberhasilan aktivitas organisasi.

\section{Sosialisasi Program}

Sosialisasi program merupakan langkah awal yang menetukan keberhasilan program dalam mencapai tujuan, oleh karena itu sosialisasi program harus dilakukan agar semua informasi tersampaikan dan dapat dipahami oleh seluruh pegawai di Rumah Sakit Ortopedi Soeharso Surakarta agar tujuan yang direncanakan bisa tercapai dengan baik. Menganalisis dan menetukan efektivitas mengenai sosialisasi program terdapat sebagai berikut :

Tabel 3. Distribusi Responden Berdasarkan Sosialisasi Program

\begin{tabular}{|c|c|c|c|}
\hline No & Kategori & Frekuensi $(\mathbf{F})$ & Persen (\%) \\
\hline 1. & Tidak Pernah & 23 & 44,2 \\
\hline 2. & Pernah & 29 & 55,8 \\
\hline & Total & 52 & 100 \\
\hline
\end{tabular}

Berdasarkan tabel diatas dari 52 responden yang menjawab terdapat 29 responden dengan presentase 55,8\% menjawab bahwa kemudahan akses pelaporan dalam menyampaikan pengaduan atas indikasi penyimpangan korupsi telah berjalan dengan baik. Sosialisasi program, yaitu kemampuan penyelenggaraan program dalam melakukan sosialisasi program sehingga informasi mengenai pelaksanaan program dapat tersampaikan kepada masyarakat pada umumnya dan sasaran peserta program pada khususnya. Menurut Wilcox dalam (Mardikonto T Dan Soebianto. P., 2013) memberikan informasi merupakan langkah awal yang dilakukan untuk mendapatkan hasil yang lebih maksimal dan memperlancar dalam melanjutkan suatu pekerjaan, karena dengan memberikan informasi dapat dipergunakan dan meningkatkan pengetahuan bagi orang yang menerima informasi tersebut.

\section{Tujuan Program}

Tujuan merupakan pedoman dalam pencapaian program. Tujuan program merupakan faktor utama dalam menentukan efektivitas suatu program. Tujuan program pelaporan whistleblowing system di Rumah Sakit Ortopedi Soeharso Surakarta adalah mewujudkan terselenggaranya tata Kelola pemerintahan yang baik 
bebas dari korupsi. Menentukan efektivitas tujuan program pelaporan whistleblowing system sebagai berikut :

Tabel 4. Distribusi Responden Berdasarkan Tujuan Program

\begin{tabular}{rrcc}
\hline No & Kategori & Frekuensi $\mathbf{( F )}$ & Persen $(\boldsymbol{\%})$ \\
\hline 1. & Tidak Tercapai & 13 & 25,0 \\
2. & Tercapai & 39 & 75,0 \\
& Total & 52 & 100 \\
\hline
\end{tabular}

Berdasarkan tabel diatas dari hasil menyebar kuesioner kepada 52 responden didapat bahwa tujuan dari program pelaporan whistleblowing system di Rumah Sakit Ortopedi Soeharso Surakarta secara efektif tujuanya sudah tercapai berdasarkan jawaban dari 39 responden dengan presentase 75,0\%.

Menurut Duncan dalam Streers menyebutkan bahwa pencapaian tujuan adalah keseluruhan upaya pencapaian tujuan harus dipandang sebagai suatu proses. Oleh karena itu, agar pencapaian tujuan akhir semakin terjamin, diperlukan pentahapan baik dalam arti pentahapan pencapaian bagian-bagiannya maupun pentahapan dalam arti periodesasinya. Pencapaian tujuan terdiri dari beberapa faktor yaitu : kurun waktu dan sasaran yang merupakan target yang kongkrit.

\section{Pemantauan Program}

Pemantauan program perlu dilakukan sebagai langkah monitoring dan evaluasi pelaksanaan pelaporan whistleblowing system di Rumah Sakit Ortopedi Soeharso Surakarta. Pemantauan program dilakukan oleh SPI (Satuan Pengawas Intern) Rumah Sakit Ortopedi Soeharso Surakarta dengan melakukan pengawasan terhadap semua laporan tindak pidana korupsi di website http://pbak.rso.go.id/ .

Menganalisis dan menetukan efektivitas mengenai pemantauan program terdapat sebagai berikut :

Tabel 5. Distribusi Responden Berdasarkan Pemantauan Program

\begin{tabular}{rrcc}
\hline No & Kategori & Frekuensi $(\mathbf{F})$ & Persen $(\boldsymbol{\%})$ \\
\hline 1. & Tidak Terlaksana & 9 & 17,3 \\
2. & Terlaksana & 43 & 82,7 \\
\hline \multicolumn{5}{c}{ Total } & 52 & 100 \\
\hline
\end{tabular}

Berdasarkan tabel diatas dari hasil menyebar kuesioner kepada 52 responden didapat bahwa 43 responden dengan presentase $82,7 \%$ menunjukan bahwa pemantauan program pelaporan whistleblowing system di Rumah Sakit Ortopedi Soeharso Surakarta sudah terlaksana. Pelaksanaan whistleblowing system RS Ortopedi Prof DR. R. Soeharso Surakarta sudah cukup efektif dalam mengurangi tindak pidana korupsi dan adanya perubahan budaya kerja setelah penerapan whistleblowing di RS Ortopedi Prof DR. R. Soeharso Surakarta.

Pemantauan program pelaporan whistleblowing system di Rumah Sakit Ortopedi Soeharso Surakarta sudah dilaksanakan oleh Satuan Pengawas Internal. Pelaksanaan whistleblowing system RS Ortopedi Prof DR. R. Soeharso Surakarta sudah cukup efektif dalam mengurangi tindak pidana korupsi serta SPI (Satuan Pengawas Intern) RS Ortopedi Prof DR. R. Soeharso Surakarta selalu melakukan pengawasan terhadap semua laporan tindak pidana korupsi di website http://pbak.rso.go.id/ . 
Pemantauan program, yaitu kegiatan yang dilakukan setelah dilaksanakan program sebagai bentuk perhatian kepada peserta program. Selanjutnya menurut Winardi (2010:7), pengawasan meliputi tindakan mengecek dan membandingkan hasil yang dicapai dengan standar-standar yang telah digariskan. Apabila hasil yang dicapai menyimpang dari standar yang berlaku perlu dilakukan tindakan korektif untuk memperbaikinya. Selanjutnya menurut Bohari pengawasan merupakan suatu bentuk pemeriksaan atau pengontrolan dari pihak yang lebih kepada bawahannya. Siagian dalam Situmorang Dkk menyebutkan bahwa pengawasan merupakan proses pengamatan daripada pelaksanaan seluruh kegiatan organisasi untuk menjamin agar supaya pekerjaan yang sedang dilakukan berjalan sesuai dengan rencana yang telah ditetapkan sebelumnya.

\section{KESIMPULAN}

Berdasarkan hasil penelitian yang ditemukan mengenai efektivitas pelaksanaan whistleblowing system di Rumah Sakit Ortopedi Soeharsa Surakarta bahwa sasaran program sudah tepat dilakukan dalam melaksanakan Whistleblowing System di Rumah Sakit Ortopedi Soeharso Surakarta dengan pegawai mempercayakan kepada pihak yang berwenang terhadap apa yang dilaporkan melalui whistleblowing system dan pegawai akan melaporkan rekan kerja jika dia ketahuan melakukan tindakan korupsi, sosialisasi program telah dilakukan oleh Satuan Pengawas Internal Rumah Sakit Ortopedi Soeharso Surakarta dengan mensosialisasikan metode pengaduan whistleblowing system dengan mudah dan mudah diakses, tujuan program pelaporan whistleblowing system di Rumah Sakit Ortopedi Soeharsa Surakarta sudah terlaksana bahwa tujuannya untuk menghentikan perilaku tindakan korupsi dan sebagai salah satu upaya mencegah tindak korupsi, pemantauan program yang dilakukan oleh Satuan Pengawas Internal sudah terlaksana dalam melakukan pengawasan terhadap semua laporan tindak pidana korupsi di website http://pbak.rso.go.id/

\section{SARAN}

Penelitian lebih lanjut bisa melakukan dengan menghubungkan antar vairbel terhadap efektifitas pelaksanaan whistleblowing system sebagai upaya pencegahan tindakan korupsi pada bidang kesehatan.

\section{DAFTAR PUSTAKA}

Anti-Corruption Clearing House. (2017) Tindakan Korupsi Berdasarkan Jenis Perkara. Available at: https://acch.kpk.go.id/id/statistik/tindak-pidanakorupsi/tpk-berdasarkan-jenis-perkara.

Indonesia Corruption Watch (2017) 'Tren Korupsi Kesehatan'. Available at: https://antikorupsi.org/sites/default/files/files/Siaran Pers/Tren Korupsi Kesehatan 2017.pdf.

Indonesian Corruption Watch (2018) Laporan Tren Penindakan Kasus Korupsi Tahun 2018.

Kementerian Keuangan (2020) Anggaran Kesehatan. Available at: http://www.dataapbn.kemenkeu.go.id/Dataset/Details/1008.

Makmur (2011) Efektivitas Kebijakan Kelembagaan Pengawasan. Bandung: Refika 
Aaditama.

Malek, J. (2015) 'To Tell or Not to Tell ? The Ethical Dilemma of the To Tell or Not to Tell? The Ethical Dilemma of the Would-Be', 9621(November). doi: $10.1080 / 08989621003791929$.

Marcia P. Miceli, Janet P. Near, and T. M. D. (2009) 'Whistle-blowing in Organizations', Administrative Science Quarterly, 54(2), pp. 344-346. doi: https://doi.org/10.2189\%2Fasqu.2009.54.2.344.

Mardikonto T Dan Soebianto. P. (2013) Pemberdayaan Masyarakat Dalam Perspektif Kebijakan Publik. Bandung: Alfabeta.

Miceli, M. P. et al. (2012) 'Predicting employee reactions to perceived organizational wrongdoing: Demoralization, justice, proactive personality, and whistleblowing', Human Relations, 65(8), pp. 923-954. doi: $10.1177 / 0018726712447004$.

Srividhya, M. S. and Stalin, S. C. (2012) 'Whistle Blowing Porotection - a Watch Dog for the Organisation', IRJC International Journal of Social Science \& Interdisciplinary Research, 1(10). Available at: www.indianresearchjournals.com.

Transparency International (2017) 'Global Corruption Barometer 2017'.

Transparency International (2018) Corruption Perceptions Index 2018. Available at: https://www.transparency.org/cpi2018. 